\title{
Guest Note
}

\section{The Most Important Legislation Facing Humanity? The Proposed EU Regulation on Artificial Intelligence}

\author{
Eduardo Gill-Pedro*
}

At the start of his recent book Human Compatible, Stuart Russell poses what he considers "possibly the most important question facing humanity". ${ }^{1}$ The question is what happens if we succeed in creating human-level or superhuman artificial intelligence. Whilst we are nowhere near developing such systems ${ }^{2}$ and we may never be, most would nonetheless agree that artificial intelligence (AI) is set to be "one of the most transformative forces of our time, and is bound to alter the fabric of society". ${ }^{3}$

AI technologies have the potential to bring tremendous benefits to the companies and organisations who use them, as well to society in general: it is expected to bring about substantial increases in productivity, innovation, growth and job creation. ${ }^{4}$ As AI capabilities improve, it may provide us with the answer to some of the world's most intractable problems, such as climate change, widespread poverty or resource depletion. ${ }^{5}$ We have had a little insight into that transformative potential during the current Covid-19 pandemic: AI has played a key role in the rapid development of the vaccines against the SARS-CoV-2 virus, ${ }^{6}$ and is being deployed in both the tracking of the spread of the disease and in planning the effective distribution of the vaccine. ${ }^{7}$

On the other hand, AI technologies have the potential to "radically transform welfare, wealth, or power", 8 and these transformations will probably not all be benign. AI may exacerbate existing inequalities, ${ }^{9}$ entrench structures of discrimination, ${ }^{10}$ bring about mass

\footnotetext{
* Associate Professor and Ragnar Söderberg Senior Research Fellow, Faculty of Law, Lund University.

${ }^{1}$ Stuart Russell, Human Compatible: Artificial Intelligence and the problem of control (Viking, 2019).

${ }^{2}$ Many AI researchers are skeptical of the possibility of developing human or superhuman level artificial intelligence in this century, though there are others that consider it may occur within the next 30 to 50 years. All appear to agree that it is very difficult to forecast. (AI Impacts 'Surveys on Fractional Progress towards HLAI' (2016) at <https:/ / aiimpacts.org/surveys-on-fractional-progress-towards-hlai/)>.

${ }^{3}$ High Level Expert Group 'Draft Ethics Guidelines for Trustworthy AI ‘ (European Commission, 18 December 2018), p. i.

4 James Eager et al, 'Opportunities of Artificial Intelligence' (Report for the European Parliament, PE 652713,2020 )

${ }^{5}$ Russell (n 1), 98.

${ }^{6}$ Arash Arshadi et al, 'Artificial Intelligence for COVID-19 Drug Discovery and Vaccine Development' (2020) 3 Frontiers in Artificial Intelligence 65.

${ }^{7}$ Susan Caminiti 'How AI is helping the Covid 19 vaccine roll-out', Nasdaq News, 9 December 2020, at $<$ https://www.nasdaq.com/articles/how-ai-is-helping-the-covid-19-vaccine-roll-out-2020-12-09>.

8 Alan Dafoe 'AI Governance: a research agenda' (Future of Humanity Institute, 2018).

${ }^{9}$ Cristian Alonso, et al 'Will the AI Revolution Cause a Great Divergence?' IMF Working Paper 2020/184, at <https://www.imf.org/en/Publications/WP/Issues/2020/09/11/Will-the-AI-Revolution-Cause-a-GreatDivergence-49734.>

${ }^{10}$ Phillip Hacker, 'Teaching Fairness to Artificial Intelligence: Existing and Novel Strategies against Algorithmic Discrimination under EU Law’ (2018) 55 Common Market Law Review 1143.
} 
unemployment, ${ }^{11}$ and increase the power of dominant market actors. ${ }^{12}$ The use of AI technologies may facilitate mass surveillance, enhance the state's ability to control its citizens, ${ }^{13}$ and undermine democratic processes. ${ }^{14}$ Already the use of AI in a number of fields is giving rise to ethical concerns in respect of privacy and data protection; discrimination, accountability and liability. ${ }^{15}$ The Covid 19 pandemic has unfortunately also provided an insight into the potential negative impact of AI - from helping to speed up the spread of disinformation about the vaccine to facilitating the covert monitoring of individuals private lives. $^{16}$

In light of these enormous actual and potential impacts of AI on our society, the debate as to whether, and if so how, to regulate AI has grown in intensity. ${ }^{17}$ While some affirm that specific AI regulation as unnecessary and premature, ${ }^{18}$ and as stifling the development of the enormous potential of this technology ${ }^{19}$ others argue that regulation is vital both to prevent potentially catastrophic risks, ${ }^{20}$ and to ensure that the enormous potential of AI to improve the lives of billions of lives is realized. ${ }^{21}$

\section{Enter the EU}

On 21 April 2021 the European Commission issued a proposal for a Regulation on Artificial Intelligence. $^{22}$. The proposal is the outcome of a long running process, that included the setting up of a High Level Expert Group, bringing together representatives from academia, civil society and industry. The Group engaged with a wide range of actors, and produced a

\footnotetext{
${ }^{11}$ Eager (n 4) 9.

12 Jacques Cremér et al 'Competition Policy for the Digital Era' (European Commission Report, 2019), at >https://ec.europa.eu/competition/publications/reports/kd0419345enn.pdf>.

13 Birgit Schippers, 'Artificial Intelligence and Democratic Politics' (2020) 11 Political Insight 32.

${ }^{14}$ There are those who argued that this is already started to happened, pointing to evidence related to the US elections in 2016 and the Brexit referendum in the UK. (Vyacheslav Polonski 'How artificial intelligence conquered democracy' The Conversation, 8 August 2017 at <https://theconversation.com/how-artificialintelligence-conquered-democracy-77675)>.

${ }^{15}$ Eager (n. 4), p. 10. For an overview of the actual and potential human rights impact of AI, see CAHAI Secretariat 'Towards regulation of AI systems (Council of Europe, 2020), at

$<$ https://www.coe.int/en/web/artificial-intelligence/-/-toward-regulation-of-ai-systems->.

${ }^{16}$ Laura Spinney, 'Let's make sure our personal data works for us - not against us - after the pandemic', The Guardian, 21 May 2021, at <https://www.theguardian.com/commentisfree/2021/may/21/data-workingfor-us-covid-pandemic-information-sharing-rights $>$.

17 Amitai Etzioni and Oren Etzioni ‘Should Artificial Intelligence be Regulated (2017) 33 Issues in Science and Technology 4.

${ }^{18}$ House of Lords Report AI in the UK: No room for complacency (2020) HL Paper 196

<https://publications.parliament.uk/pa/ld5801/ldselect/ldliaison/196/196.pdf>; Chris. Reed 'How should we regulate artificial intelligence' (2018) Philosophical Transactions of the Royal Society 376.

${ }^{19}$ Gonenc Gurkaynak et al, 'Stifling Artificial Intelligence: Human perils' ((2016) 32 Computer Law and Security Review 5.

20 'Stuart Dredge, 'Artificial Intelligence and Nanotechnology 'threaten civilization' The Guardian 18 February 2015, at <https://www.theguardian.com/technology/2015/feb/18/artificial-intelligence-nanotechnologyrisks-human-civilisation $>$.

${ }^{21}$ Sunder Pichai, 'Why Google thinks we need to regulate AI' Financial Times 20 January 2020, at $<$ https://www.ft.com/content/3467659a-386d-11ea-ac3c-f68c10993b04>. Pichai is the Chief Executive of Alphabet, a company that has invested heavily in the development of AI.

22 Proposal for a Regulation of the European Parliament and of the Council Laying Down Harmonised Rules on Artificial Intelligence (2021/0106 (COD)).
} 
set of guidelines and recommendations ${ }^{23}$ which the Commission could use to anchor its proposal in a way likely to garner broad support among the relevant stakeholders.

It is clear that in issuing this proposal the EU is seeking to "stake a claim to the future of AI", 24 not only within the EU and its member states, but globally. This proposed Regulation, if passed, will be the first significant binding legal instrument regulating the development and use of artificial intelligence in the world,. This gives it the potential to shape the development of AI governance for years, perhaps decades to come: transnational governance mechanisms can be deeply path dependent, and as Chihon et all point out "decision taken early on constrain and partly determine future paths" both within a particular regime but across regimes. ${ }^{25}$ If one accepts Stuart Russell's assertion that the question concerning the control of AI is 'the most important question facing humanity' one could argue, though perhaps with some exaggeration, that the proposed Regulation is the most important piece of legislation facing humanity!

In this short note I will set out a brief overview of this provision, and provide some initial thoughts on its merits.

\section{The Draft Regulation}

The proposed Regulation has three key objectives. The first objective is market integration. ${ }^{26}$ The Regulation's primary legal basis would be Article 114 TFEU, under which the EU has competence to adopt the measures for the approximation of national law in order to facilitate the establishment and functioning of the internal market. The Explanations to the draft regulation point out that some member states are already considering introducing legislation to regulate AI. Such developments, in the view of the Commission, are likely to lead to fragmentation of the internal market, and to loss of legal certainty, as both producers and users will be uncertain of what rules will apply in the Union both now and in the future. ${ }^{27}$ The Regulation would seek to provide the uniformity and predictability necessary for the proper functioning of the internal market.

The second objective is to encourage development and innovation. The Proposed Regulation is certainly not intended as a restraint on AI - on the contrary, it is intended to "foster the development, use and uptake of AI in the internal market", ${ }^{28}$ as well as to promote the competitiveness of the EU AI industry globally. ${ }^{29}$ However, and this is the third objective, the regulation seeks to ensure that the development and deployment of AI systems in the

\footnotetext{
${ }^{23}$ See European Commissions webpage on Shaping Europe's Digital Future at $<$ https://digitalstrategy.ec.europa.eu/en/policies/expert-group-ai>.

${ }^{24}$ Brian McElligot, 'AI Regulation - the EU approach, MHC Webinar, 23 June 2020, at

$<$ https://www.youtube.com/watch?v=n8QvWxIvjtI $>$.

25 Peter Cihon et al, 'Fragmentation and the Future: Investigating Architectures for International AI

Governance' (2020)11 Global Policy 545

${ }^{26}$ Proposed Regulation, recital 1.

${ }^{27}$ Explanatory Memorandum to the Proposal for a Regulation of the European Parliament and of the Council laying down harmonised rules on artificial intelligence Comm(2021) 206 Final

28 Proposal (n 22), recital 5.

29 According to the Proposal "A common EU legislative action on AI could boost the internal market and has great potential to provide European industry with a competitive edge at the global scene” (p. 94).
} 
internal market is accompanied by conditions that provide for a 'high level of protection of public interests' including a high level of protection of fundamental rights. ${ }^{30}$

These objectives are deeply interlinked, and underpinning them all is the concept of 'trustworthiness'. As the Commission put it, this Regulation is:

Part of the European Union's efforts to be an active player in international and multilateral fora in the field of digital technologies and a global leader in the promotion of trustworthy $\mathrm{AI}^{31}$

Note that this Regulation is but a part of the EU's efforts. This Proposal is part of a package. It was released together with a Communication on Fostering an European Approach on $\mathrm{AI}^{32}$ as well as the annexed Coordinated Plan with Member States on AI. ${ }^{33}$ These measures set out the path which the Commission hopes will make the EU "a global leader in the promotion of trustworthy AI". They also build on two proposals that are already on the legislative train - the Proposal for a Digital Services Act ${ }^{34}$ and the Proposal for a Digital Markets Act. There is a clear conscious attempt on the part of the EU, and in particular of the Commission, to position the Union as an "active player in international and multilateral fora in the field of digital technologies" and to:

Spearhead the development of new ambitious global norms, AI-related international standardisation initiatives and cooperation frameworks in line with the rules- based multilateral system and the values it upholds. ${ }^{35}$

The intended outcome of this legislative activity has been claimed to be nothing less than "a new Code Napoléon for the internet and for the digital society". ${ }^{36}$

\section{Regulatory Framework}

The proposal is clearly intended to cast the regulatory net fairly wide, by providing a broad definition of $\mathrm{AI}^{37}$ to begin with, and by endowing the Commission with the power to include

\footnotetext{
30 ibid. The Explanatory memorandum mentions two separate objectives: ensuring that AI systems are safe and respect existing law on fundamental rights, and enhancing "governance and effective enforcement of existing law on fundamental rights and safety requirements applicable to AI systems". I suggest that these two 'objectives' are merely the substantive and procedural aspects of the objective of ensuring AI safety. ${ }^{31}$ Communication from the Commission Fostering a European approach to Artificial Intelligence (COM2021/205).

32 ibid.

33 Annex to Comm2021/2015, 21 April 2021

34 Proposal for a Regulation of the European Parliament and Council on a Single Market For Digital Services (COM/2020/825 final).

${ }^{35}$ Communication (n 31).

${ }^{36}$ Paul Nemitz (Principal Adviser on Justice Policy - EU Commission) in Webinar on 'AI Regulation in Europe: What is the right mix?” (Giurispudenza Roma Tre, 1 June 2021, available at:

$<$ https://www.youtube.com/watch?v=pZu-WPplj9E $>$.

37 Article 3(1) of the proposed Regulation defines AI as "software that is developed with one or more of the techniques and approaches listed in Annex I and can, for a given set of human-defined objectives, generate outputs such as content, predictions, recommendations, or decisions influencing the environments they interact with." The techniques set out in Annex I are: a) machine learning approaches, logic and knowledge based approaches and statistical approaches.
} 
other types of applications by means of delegated legislation ${ }^{38}$ in order to 'future-proof the legislation.

The proposal aims for targeted and proportionate regulatory intervention, by taking a risk based approach that distinguishes between AI applications and practices that entail unacceptable risk, high risk, limited risk or minimal risk. ${ }^{39}$

Practices that entail an unacceptable risk are to be prohibited. ${ }^{40}$ This covers practices such as subliminal techniques that distort a person's behavior, practices that exploit children or vulnerable persons, social scoring technologies and the most categories of use of 'realtime' biometric identification (such as face-recognition) in public places. ${ }^{41}$

High risk systems are those that are considered to pose "significant risks to the health and safety or fundamental rights of persons". ${ }^{42}$ They include AI used as part of safety components of products, AI systems used in critical infrastructure or in essential public services, systems used in education, recruitment, law-enforcement, immigration decisions or administration of justice. ${ }^{43}$ Again, the legislation is 'future proofed' by empowering the Commission to add categories of systems to the high-risk list, by means of delegated legislation. ${ }^{44}$

The primary regulatory burden is borne by the 'providers' of the AI system. ${ }^{45}$ Providers can only place high risk AI systems on the market if they: ${ }^{46}$

- Put in place an adequate risk management system,

- Use high quality data sets,

- Include technical documentation that shows how the system complies with the requirements of the Regulation,

- Provide for accurate record keeping that ensures traceability and monitoring of the system's functioning throughout its lifecycle,

- Design the system in such a way to ensure that its operation is sufficiently transparent to enable users to interpret the system's output and use it appropriately,

- Design the system in a way that allows for human oversight throughout its operation,

- Design and develop the system so to achieve an appropriate level of accuracy, robustness and cybersecurity in light of its intended purpose.

Systems that are not prohibited or classified as high-risk generally escape regulation, except in respect of some systems (use of chat-bots, production of deep-fake photos or videos) where there are some transparency requirements.

\footnotetext{
${ }^{38}$ By adding to or amending the techniques set out in Annex I, as provided for by Article 4.

39 Proposal (n 22), Explanatory Memorandum, p. 12.

40 Proposal (n 22), Article 5.

${ }^{41}$ Thought there are exceptions that allow the use of real time biometric identification where this is strictly necessary for specified objectives.

42 Proposal (n 22), Explanatory Memorandum, p. 13.

${ }^{43}$ Proposal (n 22), Article 6. The detailed list of systems is set out in Annex III to the proposal.

44 Proposal (n 22), Article 7.

45 According to Article 3(2) of the proposed Regulation, provider means a person, or other entity that develops an AI system or has it developed with a view to placing it on the market. There are also some duties imposed on users, importers and distributors.

46 The following requirements are set out in Articles 9- 15 of the proposed Regulation.
} 


\section{Governance Structure}

While some types of AI systems ${ }^{47}$ will require conformity assessments carried out by third parties, ${ }^{48}$ on the whole the burden on ensuring that the systems conform with the requirements above is placed mostly on the providers themselves. Providers of AI systems classified as 'high-risk' have to put in place a comprehensive system of ex-ante conformity assessment through internal checks. ${ }^{49}$ This self-regulation mechanism is backed by national authorities, who are empowered to require providers to supply "all the information and documentation necessary to demonstrate ... conformity". ${ }^{50}$ National authorities are empowered to impose very significant penalties on undertakings who fail to comply with their obligations under the Regulation. ${ }^{51}$ There is no requirement for member states to establish dedicated 'AI authorities' as member states can designate existing authorities, such as market surveillance authorities, as supervisory authorities. ${ }^{52}$

National authorities will be able to set up 'regulatory sandboxes': controlled environments intended to facilitate "the development, testing and validation of innovative AI systems for a limited time before their placement on the market". ${ }^{53}$

The operation of this governance structure will be overseen by the proposed European Artificial Intelligence Board. This Board will facilitate cooperation between national authorities and between these authorities and the Commission, and guide the development of standards for $\mathrm{AI}$ across the EU. ${ }^{54}$

\section{Initial thoughts}

The introduction of this proposal can be seen as the EU 'putting a marker in the sand' which will set the framework around which the debate on AI governance will revolve, not only in Europe, but internationally.

In introducing the proposal, the Commission appears to show a commitment to the position that AI should be regulated as a discrete and specific phenomenon. The idea, advanced by some, that ethical principles rather than hard law should guide the development of these technologies, has been rejected. However, as Lucilla Sioli, the Commission official that had a lead role in drafting the Regulation, put it, the proposal is not for the regulation of $\mathrm{AI}$ as such, but for the regulation of specific uses or applications of AI. ${ }^{55}$

Therefore, while there can be concern that the proposed regulation will add complexity to the European regulatory landscape, and so impose greater burdens on AI developers and

\footnotetext{
47 AI systems which are components of products, or which are themselves products, which require certification under existing EU product safety legislation, as well as AI systems for remote biometric identification.

48 Proposal (n. 22), Article 43.

49 ibid, Explanations, p 14. The detailed obligations are set out in Article 16.

50 ibid, Article 23.

51 ibid, Article 71 . The administrative fines for non-compliance can be up to 30 million Euros, or $6 \%$ of global turnover.

$52 \mathrm{ibid}$, Article 59. However member states need to ensure that these authorities have the relevant expertise and resources to fulfil their supervisory tasks (Article 59(4)).

53 ibid, Article 53.

$54 \mathrm{ibid}$, Articles 56 and 58.

${ }^{5}$ CEPS Webinar 'A European approach to the regulation of artificial intelligence' 23 April 2021, at

$<$ https://www.ceps.eu/ceps-events/a-european-approach-to-the-regulation-of-artificial-intelligence $>$.
} 
manufactures, ${ }^{56}$ the tenor of the proposal is that the development and use of AI in the European single market is to be encouraged and nurtured. The Commission's risk- based approach to regulation means that the majority of AI uses, which are not considered at the moment to present significant risks, are not subject to regulatory measures. The proposed Regulation will also prevent member states from imposing stricter rules on domestic developers, or to restrict the use, in their territory, of AI developed in other member states that complies with the provisions of the Regulation. ${ }^{57}$ In addition, there are specific provisions, in particular the requirements to put in place regulatory sandboxes, that are specifically intended to foster innovation and experimentation.

The question will be whether the proposed 'European approach' to AI regulation will succeed in increasing the trustworthiness of the AI. There are uses of AI that have raised significant concerns, such as the algorithms used to track user preferences in social media or retail platforms, which appear to escape regulation. And while the proposal prohibits the use of "real-time remote biometric identification systems in publicly accessible spaces for the purpose of law enforcement" except in very limited circumstances., ${ }^{58}$ this prohibition turns out to be quite narrowly defined, and appears to permit the use of such systems for other purposes than law enforcement, or where the identification is not done in real-time. One striking example of the latitude afforded by the proposed regulation is that AI systems that use biometric data "for the purpose of assigning natural persons to specific categories, such as ... ethnic origin or sexual or political orientation," are not prohibited, but are merely required to inform the persons exposed to this system that they are being categorized in this way by a machine. ${ }^{59}$ In addition to these apparent gaps in the substantive regulatory standards, there are weaknesses in the procedures for enforcing these standards. Much of the work of assessing the risk level of the AI system, and of ensuring that the systems conform with the requirements of the regulation, is left for the developers of the AI systems themselves - the regulation relies to a great extent on self-assessment of conformity.

Of course, this proposal is just that - a proposal. The work of the legislator now is to address these potential weaknesses and to ensure that the final regulation has the best possible chance of achieving the Union's objective of fostering an innovative, human-centric and trustworthy AI industry. The task of all of us who consider that such an outcome is important is to engage with this proposal, and to participate in its design and improvement. It is likely that in the next few months and years crucial decisions about the governance over the development and use of AI systems will be made. Those decisions may have wide-ranging impacts on the future of humanity, and this proposed regulation is an important element in that process.

\footnotetext{
${ }^{56}$ Especially considering that many applications are likely require compliance with a range of instruments, including the GDPR or sector specific product safety or market regulation.

57 The proposed regulation will be total harmonization measure.

58 Proposal (n. 22), Article 5(1)(d).

59 ibid, Article 52(2).
} 